\title{
Iniciativas de Inserção de Mulheres no Mercado de Tecnologia da Informação: Análise das experiências de participantes brasileiros do Desafio Technovation
}

\author{
Suzy Santiago, Carolina Riente de Andrade \\ Programa de Pós-Graduação Lato Sensu MBA em Gestão de Tecnologia da Informação \\ Centro Federal de Educação Tecnológica de Minas Gerais (CEFET-MG) \\ 30.510-000 - Belo Horizonte - MG - Brasil \\ \{yzus9000, profcarolinariente\}@gmail.com
}

\begin{abstract}
This paper presents a case study of the Technovation Challenge, an international project that aims to raise the interest of girls in areas related to technology, in order to explore how the initiatives promoted by the project contribute to increase the female presence in these areas, which are predominantly male. Questionnaires were applied to project participants in 2017 and from these qualitative and quantitative analyzes were carried out to verify the contributions of the project.
\end{abstract}

Resumo. Este artigo apresenta um estudo de caso do Desafio Technovation, um projeto de âmbito internacional, que se propõe a despertar o interesse de meninas em áreas relacionadas à tecnologia, de forma a explorar como as iniciativas promovidas pelo projeto contribuem para aumentar a presença feminina nestas áreas, que são predominantemente masculinas. Foram aplicados questionários para participantes do projeto no ano de 2017 e partir destes foram realizadas análises qualitativas e quantitativas para verificar as contribuições do projeto.

\section{Introdução}

Os cursos de computação são predominantemente masculinos, e como consequência, assim também é o mercado de Tecnologia da Informação (TI). Somente um quarto do setor de TI é formado por mão de obra feminina, de forma que os números comprovam a prevalência masculina neste setor (IAB Brasil, 2015). [IAB Brasil 2015]. O relatório The future tech workforce: breaking gender afirma que os executivos estão encontrando dificuldades para contratar profissionais qualificados na área de tecnologia e que as mulheres representam uma minoria nessa área, o que colabora para a carência de inteligência e inovação no setor, impedindo o crescimento das empresas [ISACA 2016].

Diversas iniciativas começaram a ser desenvolvidas, não só por mulheres, que se sentem incomodadas com este gap de gênero no setor de TI, mas também por empresas, que não se limitam a aceitar a situação de forma passiva e se unem para criar projetos para atrair cada vez mais mulheres para a área. Projetos com esta ideação já são encontrados em todo o mundo. Só no Brasil, existem diversos grupos com esse ideal, como o Anitas, de Florianópolis, que organiza cursos, palestras e workshops e participa 
de outras iniciativas que também almejam incluir mais mulheres na área de tecnologia. O Meninas na Ciência da Computação é um projeto coordenado por professoras do Centro de Informática da Universidade Federal da Paraíba e que conta com escolas de Ensino Médio da Paraíba, que visa disseminar conhecimentos de forma a atrair mulheres para as carreiras em STEM ${ }^{1}$ (MARQUES, 2016). A gigante Google criou e mantém diversos programas com esse propósito, como por exemplo, o Women Techmakers “[...]marca global do Google voltado para as mulheres na tecnologia. Atualmente, o programa foca em empoderar as mulheres na tecnologia através do aumento da visibilidade, comunidade e recursos destinados à elas." (WOMEN TECHMAKERS BRASIL, 201-). O programa oferece várias ações, como por exemplo, conceder bolsas de estudos em graduações e pós-graduações para meninas, realizar encontros com mulheres para falar sobre ferramentas e plataformas do Google e oferecer bolsas de estudos para cursos sobre tecnologias da empresa.

Este artigo apresenta um estudo de caso do Desafio Technovation, um projeto de âmbito internacional, que se propõe a despertar o interesse de meninas em áreas relacionadas à tecnologia, de forma a explorar como as iniciativas do projeto colaboram para despertar o interesse de meninas em TI e consequentemente para aumentar o número mulheres nesse setor.

\section{Metodologia}

Este estudo de caso é uma pesquisa social de natureza descritiva e exploratória, que se propõe analisar experiências de participantes brasileiros do Desafio Technovation no ano de 2017. Para o alcance dos objetivos, foram utilizados os métodos qualitativos e quantitativos. Contatos de participantes brasileiros foram conseguidos através de canais do projeto (como sites e organizadores) e questionários foram enviados para os mesmos de forma a coletar os dados necessários para posterior análise.

Não foi possível mensurar o universo de participantes do Desafio Technovation 2017, uma vez que o projeto é de âmbito internacional e que esses dados não são apresentados nos canais de comunicação do mesmo. Dessa forma, a amostra deste estudo foi constituída de 46 participantes ( 8 embaixadores, 13 mentores e 25 estudantes) do Desafio Technovation 2017, habitantes de oito estados brasileiros.

Foram elaborados três modelos de questionários (um para cada perfil de participante) na plataforma virtual do Google $\operatorname{Docs}^{\circledR}$ no aplicativo editor de formulários. Os questionários foram disponibilizados para os participantes através de um link enviado por e-mail. Nem todos os participantes que receberam os questionários participaram da pesquisa, uma vez que a adesão era voluntária. Os dados apresentados neste artigo são um recorte dos pontos mais relevantes de uma monografia que apresenta os dados completos do estudo.

\section{Apresentação e Análise dos Dados}

\subsection{O projeto}

O projeto estudado é uma competição em que estudantes do Ensino Fundamental e

\footnotetext{
${ }^{1}$ STEM (Science, Technology, Engineering and Mathematics).
} 
Médio formam times para criar aplicativos que ajudem a resolver problemas da sociedade, baseados em temas específicos (pobreza, meio-ambiente, paz, igualdade, educação e saúde).

O projeto não avalia apenas os aplicativos desenvolvidos pelos times, mas todo o processo de criação, o que inclui desde a ideação dos aplicativos até o desenvolvimento e apresentação para o mercado. Desta forma, os times realizam diversas atividades ao longo de sua participação no projeto, de maneira que as estudantes adquiram não somente conhecimentos na área tecnológica, mas também sobre o desenvolvimento de um negócio, despertando o empreendedorismo. Os times são suportados por mentores que os ajudam a atingir os objetivos do projeto.

\subsection{Vivência de estudantes}

Um total de 25 estudantes respondeu um questionário para falar sobre as experiências e impressões que tiveram ao participar do projeto. Os três estados brasileiros com maior número de estudantes participantes do estudo foram Minas Gerais (40\%), Pará e São Paulo (16\% cada). Entre as estudantes, 93\% cursavam o Ensino Médio, e dessas, a maioria cursava o $3^{\circ}$ ano (68\%). A maior parte das estudantes afirmou que recebeu apoio da família para participar do projeto $(76 \%)$.

Com relação a motivação para participação no projeto, foram identificados nove motivos principais. Os mais citados foram 'aprender mais sobre tecnologia e ter oportunidade de criar um aplicativo' (32\%), 'ter somente participantes mulheres e valorizar o empoderamento feminino' (18\%) e 'ser um projeto filantrópico que objetiva realizar algo para o bem da sociedade' (18\%). Em função da maioria das estudantes cursarem o Ensino Médio, quando questionadas se este período escolar (de estudos para o Exame Nacional do Ensino Médio e vestibulares) tornava difícil participar de um projeto como esse (que sugeria um compromisso de no mínimo 40 a 60 horas totais de dedicação para desenvolver todas as atividades), cerca de dois terços das estudantes (67\%) afirmaram que sim, que este fato dificultava e gerava pressão e sobrecarga, pois o tempo se tornava limitado para conciliar as duas atividades.

Como um dos objetivos do projeto era o desenvolvimento de um aplicativo, as estudantes foram questionadas se todas as integrantes do time participaram desta atividade. Somente duas estudantes afirmaram não ter participado, uma vez que se tornou necessário dividir as tarefas para o time conseguir entregar tudo a tempo. Entre as integrantes que participaram do desenvolvimento dos aplicativos (23), todas afirmaram que gostaram de realizar essa atividade, que agregou muitos conhecimentos, além de se sentirem gratificadas com as conquistas em programação. Os fatores negativos mais citados pelas participantes, que influenciaram nos resultados alcançados pelos times, foram: 'falta de tempo para dedicação' e 'falta de recursos' (como locais de acesso a computadores e internet).

Embora a escolha da profissão seja algo difícil para muitos adolescentes, 84\% das estudantes afirmaram que já haviam decidido que profissão seguir após concluírem o Ensino Médio antes de participar do projeto. Entre estas estudantes (21), 62\% pretendem seguir carreiras de tecnologia. Considerando as estudantes indecisas (4), duas afirmaram que pretendem seguir alguma área de tecnologia após participar do projeto, uma ainda se manteve indecisa e outra não pretende entrar no mercado de tecnologia. 


\subsection{Vivência de mentores}

Participaram deste estudo 13 voluntários que atuaram como mentores dos times. Os dois estados brasileiros com maior número de mentores participantes do estudo foram Minas Gerais (31\%) e São Paulo (23\%). Entre os mentores, $85 \%$ eram de áreas exatas, sendo que, 69\% eram de áreas de tecnologia. Cerca de 69\% dos mentores nunca havia participado do projeto em edições anteriores.

Questionados sobre a motivação para participar como voluntários no projeto, os mentores afirmaram ter quatro motivos principais: 'aumentar o número de mulheres em carreiras de STEM ou empoderar mulheres em computação' (40\%), 'fazer o bem e contribuir para o desenvolvimento de pessoas' (30\%), 'compartilhar experiências na área, inclusive as frustações e discriminações de gênero' (25\%) e 'melhorar o próprio currículo'(5\%).

Quando questionados se sugeriram ou concordaram que a atividade de desenvolvimento do aplicativo fosse dividida entre as estudantes, somente um mentor afirmou que não. Os demais foram praticamente unânimes nas respostas, afirmando concordar com a divisão desta atividade porque também no mercado de tecnologia existe esta divisão no desenvolvimento, onde cada pessoa ou equipe é responsável por uma parte do aplicativo/sistema. Também alegaram ser válida esta divisão para que todas as estudantes trabalhassem com o que tivessem mais afinidade, mostrando que a tecnologia tem vários nichos de atuação.

O projeto não exige que os mentores sejam de áreas de tecnologia para conseguirem dar suporte para os times, uma vez que disponibiliza em seus canais tutoriais que ensinam a programação na plataforma sugerida de programação, para que as estudantes possam adquirir conhecimentos de maneira autodidata. Perguntados se acreditavam que o nível de programação exigido nesse projeto poderia ser alcançado pelas estudantes apenas com os materiais disponibilizados e sugeridos pelo projeto, ou se acreditavam que todos os times deveriam ter, no mínimo, um mentor da área de tecnologia para auxiliar no desenvolvimento do aplicativo, mais de $61 \%$ mentores julgou importante ter ao menos um mentor de tecnologia nos times, pois embora a plataforma de programação seja intuitiva, muitas dúvidas e dificuldades só conseguem ser sanadas por profissionais dessa área. Um dos mentores afirmou, inclusive, ter observado que times que não tinha algum voluntário de tecnologia, só conseguiram desenvolver o seu aplicativo recorrendo a mentores dessa área que participavam de outros times. De acordo com os mentores, os que fatores que mais influenciaram negativamente o desempenho dos times foram: 'falta de dedicação das estudantes' $\mathrm{e}$ 'falta de recursos', além de 'disponibilidade de estudantes e mentores', 'falta de conhecimento em negócios' (o projeto exigia elaboração de um plano de negócios do aplicativo desenvolvido) e 'traduções de materiais dos times para o idioma inglês'.

\subsection{Vivência de embaixadores}

Um total de 8 embaixadores participaram deste estudo. A principal motivação para participação no desafio apontada por eles foi 'aumentar $\mathrm{n}^{\circ}$ de mulheres em STEM' $(50,0 \%)$.

Um percentual de $62,5 \%$ de embaixadores relatou que as ações que realizaram não foram financiadas pelo projeto e 75,0\% afirmaram que encontrou dificuldades para 
divulgar o projeto e os principais motivos levantados foram 'dificuldade de conciliar horários', 'escolas públicas com pouco ou nenhum suporte tecnológico', 'boa parte da temporada acontece no período de férias escolares' e 'muitas escolas não são receptivas ao projeto'. Os embaixadores alegaram que 'falta de parcerias / dificuldade de fechar parcerias' foi um dos fatores que mais influenciaram negativamente no desempenho dos times de sua localidade.

\section{Considerações Finais}

Percebe-se que a maioria dos participantes deste estudo acreditam que o projeto cumpre seus objetivos e que por essa razão, não só voltam a participar (ou voltariam a participar) como indicam para alguém. Entretanto, conclui-se que, através deste estudo não foi possível inferir de forma generalizada que o projeto contribui para aumentar o número de mulheres em tecnologia. Isso se dá em virtude da amostra selecionada de participantes ser significativa, mas não o suficiente ao considerar o âmbito global do projeto, bem como, em razão da experiência ser uma percepção individual e que uma quantidade considerável de estudantes participantes deste estudo já manifestava interesse em áreas exatas antes de participar do projeto. A insuficiente infraestrutura e suporte do projeto também levam a questionar se o mesmo não poderia vir a desmotivar muitas estudantes para a área de tecnologia, ao invés de atraí-las.

Vale ressaltar, entretanto, que este projeto e outros semelhantes têm grande relevância, pois demonstram a preocupação que não só as mulheres, mas também as organizações passaram a ter com o gap de gênero no setor de tecnologia, deixando claro que não é preciso apenas criar projetos, mas também realizar estudos para acompanhar suas contribuições. Embora atualmente existam diversas iniciativas para reduzir o gap de gênero no setor de tecnologia, muitos estudos apresentam e descrevem essas iniciativas, mas exíguos analisam as contribuições efetivas que elas trazem, como este estudo se propôs. A pesquisadora não encontrou trabalhos com o viés deste estudo sobre o Desafio Technovation.

\section{Referências}

ISACA - Information Systems Audit And Control Association (2016). "The future tech workforce: breaking gender barriers", Disponível em: $<$ http://www.isaca.org/info/2017women-in-technology-survey/index.html>, Acesso em: 25 maio 2017.

IAB Brasil - Interactive Advertising Bureau Brasil (2015). "A liderança alfa e as empresas de TI no universo feminino", Disponível em: <http://iabbrasil.com.br/alideranca-alfa-e-as-empresas-de-ti-no-universo-feminino/>, Acesso em: 24 maio 2017.

MARQUES, Vanessa (2016). “Iniciativas em TI para mulheres no Brasil”, Disponível em: <http://blog.kendoo.com.br/2016/05/iniciativas-em-ti-para-mulheres-nobrasil/\#comments>, Acesso em: 13 nov. 2017.

WOMEN TECHMAKERS BRASIL,([201-]). Disponível em: <http://gxgbrasil.github.io/wtmbr/>, Acesso em: 13 nov. 2017. 